\title{
The effect of supply chain finance on supply chain risk, supply chain risk resilience, and performance of Vietnam SMEs in global supply chain
}

\author{
Duy Nhien Nguyen $^{a}$, Thi Thu Hoai Nguyen ${ }^{\mathrm{b}}$, Thi Tho Nguyen ${ }^{\mathrm{c}}$, Xuan Hung Nguyen ${ }^{\mathrm{d}}$, Thi Kim Thu Do ${ }^{\mathrm{e}^{*}}$ \\ and Hoai Nam Ngo
}

${ }^{a}$ Hanoi National University of Education, Vietnam

${ }^{b}$ University of Economics and Business, Vietnam National University, Hanoi, Vietnam

${ }^{c}$ Vinh University of Technology Education, Vietnam

${ }^{d}$ National Economics University, Hanoi, Vietnam

${ }^{e}$ University of Economics - Technology for Industries

${ }^{f}$ University of Economics - Technology for Industries

CH RON I C LE

Article history:

Received September 18, 2020

Received in revised format May

8, 2021

Accepted September 62021

Available online

September 62021

Keywords:

Supply chain finance

Supply chain risk

Supply chain risk resilience

Global supply chain

SMEs

\section{A B S T R A C T}

The purpose of the article is to examine the response of small and medium enterprises (SMEs) in Vietnam to supply chain finance and then have a strategy to use supply chain risk resilience to control supply chain risk and improve supply chain effectiveness and SMEs performance. The analysis results are based on three months of data collected from 890 SMEs in Vietnam. The results show that supply chain finance has a statistically significant positive impact on supply chain effectiveness, SMEs performance and supply chain risk resilience. At the same time, supply chain finance has a negative impact on the supply chain risk of Vietnam SMEs in the global supply chain. Finally, we offer recommendations to help SMEs improve supply chain effectiveness and performance through the supply chain finance tool.

(C) 2022 Growing Science Ltd. All rights reserved.

\section{Introduction}

In this age of globalization, the traditional methods of conducting business have undergone significant transformation. Therefore, corporate operations are growing increasingly sophisticated, which has drawn the serious attention of senior management to ensure the smooth operation of the company's day-to-day operations is a priority. Small and medium-sized enterprises (SMEs) are playing an important part in the development of a country's economic infrastructure, while also considering technological and scientific advancements to increase total productivity. Small and medium-sized enterprises (SMEs) must employ effective measures that will enable them to generate considerable operational and financial performance to reach such productivity. SMEs play an important role in the economy in Vietnam, creating jobs and growth. In Vietnam, SMEs account for about $90 \%$ of the total number of business establishments, creating nearly $60 \%$ of annual jobs (accounting for $42.2 \%$ of the number of employees), $44.8 \%$ of revenue, and contributing about $40 \%$ of GDP $33 \%$ of industrial output value, $30 \%$ of export value, contributing $29.3 \%$ to the state budget. Most SMEs operate in a fiercely competitive environment, so it is important to ensure that business is carried out in an even more efficient and effective manner. Managers believe that performance measurement tools can help identify weaknesses, clarify goals and strategies, and improve management processes in the business. Phan et al. (2020) shows that the frequent problems of SMEs include: lack of capital; lack of skilled workers; inadequate infrastructure; lack of management, marketing, and technical expertise; and limited applications of new technologies. In addition, external environmental factors such as rapidly changing technology, fierce competition, economic,

* Corresponding author

E-mail address: dokimthu.uneti@gmail.com (T. K. T. Do)

(c) 2022 Growing Science Ltd. All rights reserved.

doi: $10.5267 /$ j.uscm.2021.9.005 
socio-cultural, and international factors also have a significant influence on the success or failure of the enterprises. Increasing competition, increasing scale, continuous improvement and significant developments in information technology may be the reasons why performance measurement systems (PMS) in SMEs should be adjusted as needed. applied in practice. Therefore, although a PMS has been chosen appropriately to measure the performance of SMEs, problems arise in practice that make it difficult for enterprises to implement such systems (Pfohl \& Gomm, 2009).

In the international business environment, high customer expectations affect every part of the supply chain. Next-generation logistics management solutions are also making global supply chains smarter, faster, customer-centric, and more sustainable. Vietnam is a member of the WTO and is actively participating in the international integration process, through signing 12 free trade agreements, ending the negotiation of 1 agreement and continuing to negotiate. Three other agreements are also opening a large market for Vietnamese enterprises and are a great opportunity for Vietnamese products to penetrate deeper into the international market. With these agreements, enterprises investing in manufacturing in Vietnam can not only take advantage of reasonable production costs, tariffs, and open markets to easily participate in the global supply chain. At the same time, domestic and foreign enterprises will have favorable conditions to become enterprises providing input support products for end-to-end manufacturing enterprises in the market. The potential for investment in manufacturing in Vietnam and participation in the global value chain for sustainable development is huge, especially SMEs will have many opportunities to cooperate with foreign companies when Vietnam is attracting many investors around the world to find cooperation opportunities. Vietnam has also become a production point for several high-value industrial products such as mobile phones, tablets, etc. However, besides favorable conditions, Vietnamese enterprises still face difficulties when most Vietnamese SMEs have not taken advantage of opportunities due to low localization rate, only a few enterprises are qualified to participate in the global supply chain. Vietnamese SMEs face difficulties when participating in the global production network, which is the poor application of science and technology, resulting in low labor productivity, lack of experience in working with foreign enterprises, and unskilled labor. On the other hand, Vietnamese SMEs cannot meet the required prices due to high input costs such as taxes, fees, informal costs, and non-lean production. The size of enterprises is small, so Vietnamese SMEs can only meet small orders, while large orders are difficult to meet on time and lack quality processing stages, lack of appropriate management standards. In addition, Vietnamese SMEs still lack distribution channels, limited commercial capacity as well as lack of information on trends, technologies, markets, products, competitors, or suppliers. It is difficult to access capital for small and medium enterprises to ensure resources to fulfill orders when participating in the global supply chain. The spread of COVID-19 has disrupted the way global supply chains operate, making it difficult for businesses to model and assess risks. Obviously, supply chains in every country, including Vietnam, and across all economic sectors are seriously affected. Compared with other countries in the region, Vietnam has done a good job in containing the pandemic and reopening the economy. Currently, the country is gradually transitioning from the crisis response phase to the recovery phase. An important question for Vietnamese businesses now is how they can better prepare their supply chains for future crises. The supply chain of the future will not only revolve around performance and cost management but will be based on its security and adaptability.

Historically, a lack of operating history, the absence of financial documents, and newly created enterprises have been the key impediments to SMEs obtaining financing from financiers (Song et al., 2016; Song \& Wang, 2013). Recently, lenders or financial institutions established a new financing scheme called supply chain finance (SCF), which enables SMEs to optimize their working capital to achieve improved operational and financial performance. Supply chain financing (SCF) is gaining traction among SMEs as a viable alternative technique of increasing lending accessibility (Wang et al., 2013). SCF can help businesses operate better by encouraging longer payment terms and improving receivables facilities for their suppliers (Wuttke et al. 2016; Narasimhan \& Das, 1999; Tran, 2020a, 2020b). Tanrisever et al. (2012) noted that SMEs use SCF to expand their payment periods and increase their access to exchange credit to boost their working capital. Therefore, this article aims to assess the impact of supply chain finance on supply chain risk resilience of SMEs in the global supply chain. At the same time, evaluate the role of supply chain finance with effective supply chain management and firm performance for small and medium enterprises in Vietnam.

\section{Literature review}

\subsection{Supply Chain Management}

To compete in today's business environment, businesses need to be involved both in the businesses of their suppliers as well as their customers (Camerinelli, 2009; Swaminathan \& Tayur, 2003). This means that businesses need to pay more attention to the flow of materials, the design and packaging of their suppliers' products, and how to transport and preserve their products. Supply chain is defined as a system of organizations, people, information, activities, and resources involved in moving products/services from suppliers to customers. Thus, the supply chain includes not only manufacturers and suppliers, but also transportation companies, warehouses, retailers, and their customers. Supply chain operations are concerned with converting raw materials, natural resources and other components into a finished product or service delivered to the end customer. In 1980, the term Supply Chain Management (SCM) was developed to describe the role and necessity of linking key business processes, from end users to suppliers. first offer. Enterprises are linked together in a supply chain through the exchange of information about market fluctuations as well as production capacity. Through sharing relevant information, companies can optimize supply chains, thereby providing a more comprehensive and effective plan for production and distribution activities, cutting costs while offering more attractive end products. Supply chain and value chain optimization 
activities also include material cost balancing, production flow optimization, logistics work, location allocation, vehicle recruitment analysis, etc. (Dubey et al., 2017; Garrett et al., 2009; Revilla \& Saenz, 2017).

Supply chain management is the management of a NETWORK of businesses involved in delivering goods and services to consumers. It requires many different processes, including Storage, material transportation \& inventory handling \& production \& storage, transportation of finished goods from production to consumption, etc. (Sharma \& Routroy, 2016).

$90 \%$ of CEOs around the world put supply chain management first when the competition in the market is increasing, the market price and the purchasing price of goods supply are increasingly tightened. The impactful supply chain will dominate the market and the trust of customers, create shareholder value, expand strategy and reach for the business. In addition, in the current business environment, the supply chain is one of the factors that determine the competitiveness of enterprises compared to competitors in the same industry. Thanks to an efficient supply chain, large international corporations such as Dell and Wal-Mart have achieved 4-6\% higher profits than their competitors. An independent study also shows that some of the world's leading companies such as Apple, Coca-Cola, Samsung have effectively utilized their supply chains to stand out in the competitive environment, achieving price increases. Company value $40 \%$ higher than other competitors.

\subsection{Supply chain finance}

"Supply Chain Finance" - Supply Chain Finance is a set of scientific foundations in business and financial processes based on linking different parties in a transaction between buyers - sellers and organizations. finance - to reduce financial costs and improve business performance. It is a suite of solutions that optimize cash flow by allowing businesses to extend payment terms to their suppliers while suppliers get paid early. This leads to a win-win situation for buyers and suppliers. Buyers optimize working capital and suppliers generate additional operating cash flow, thereby minimizing risk across the supply chain.

SCF is not a loan: SCF is an extension of the amount payable by the buyer and is not considered a financial debt. For the supplier, it represents the sale of their actual receivables.

SCF is not tied to a single bank: SCF provides multi-banking capabilities by making it available to more than 50 financial institutions worldwide

SCF is not a factor: with SCF, $100 \%$ of the value of each invoice (minus a very small transaction fee) is paid to the supplier and there is no recourse burden on the supplier after the invoice is paid.

SCF isn't just for big companies: It offers companies of all sizes and credit ratings

The SCF does not have to be a bank: it can be self-financed by the buyer, set up without the bank's involvement for financing, or include a hybrid scheme in which financing is shared by purchasing, capital markets and financial institutions.

The COVID-19 pandemic has exposed the risks of interrupted and untimely supply of essential products and equipment due to the global spread of supply chain networks as well as many supply chains that are too dependent on production centers and major markets, especially China. In addition to optimizing production and costs, shifting investment and supply chains also aims to disperse and reduce risks. Currently, along with the strong development of science - technology and the increasingly fierce strategic competition between the US and China, the trend of shifting investment and global supply chains is showing strongly, posing giving Vietnam many opportunities and challenges (Frohlich \& Westbrook, 2001; Pham \& Phan, 2020).

\subsection{Global supply chain}

The Covid-19 pandemic has hit global trade and investment with unprecedented speed and scale. Multinational companies face a raw material supply shock, followed by a demand shock as more and more countries impose isolation and social distancing orders. Governments, businesses, and individual consumers are suddenly finding it difficult to procure basic products and materials and are forced to confront the fragility of modern supply chains.

Tradeshift, a global platform for supply chain management, shows how big the pandemic is affecting trade and demand. Specifically, in China, domestic and international trade transactions have decreased by $56 \%$ since mid-February 2021. Meanwhile, the US, UK and Europe also saw a decrease of $26 \%$ in early April and continued to decline by $17 \%$ at the end of April.

Trade has been flat in all areas affected by the blockade. Overall weekly trades on the Tradeshift platform since March 9 , 2021 are down $9.8 \%$ on average, compared to pre-Covid-19 figures.

Two side effects of the contraction in global trade have emerged. One is that it takes longer to settle an invoice, reversing the trend of faster payments than before. According to Tradeshift data, businesses took an average of 36.7 days to settle an invoice in 2019, compared with 36.8 days in 2018. During the first quarter of 2020, the average payment term rose $1.7 \%$ to 37.4 days. Second, the lack of orders through the supply chain is creating a "tide" with new orders slowing down and bills falling. The average weekly order volume on the Tradeshift platform has decreased by $15.9 \%$ since March 9, 2021. Bills fell 
$16.7 \%$ in the same period. So far, businesses are still receiving money from pre-closed orders, but those orders are drying up. The coming months could be very difficult for suppliers globally (Baihaqi \& Sohal, 2013).

In addition, extreme weather events in China are becoming a new challenge for the global supply chain. The rainy season brings with it major storms that can cause cargo to be stranded at some of the busiest container ports in the world. Heavy rains, high winds and floods this year have affected global trade, as the shipping industry is already too stressed to recover from the effects of the Covid-19 epidemic and geopolitical uncertainty. Things could get even worse in the near term, with more typhoons expected to make landfall in China this month. During the Covid-19 pandemic, the global supply chain has exposed vulnerabilities. In the healthcare sector, for example, where the scramble for protective gear has posed inherent risks in terms of inventory and single sourcing patterns. The impact of China's shutdown and its dominance in key manufacturing sectors have further highlighted the problems facing modern supply chains. With factories in China closed, manufacturers struggled to pivot to find alternative suppliers. Therefore, it is very likely that global companies will diversify their supply chains in the future, instead of relying solely on China. Manufacturing hubs such as Vietnam, Mexico and India are likely to benefit from this shift. There will be a decentralization of production capacity, and some countries will begin to repatriate links in their supply chains. This trend grows with the trend of automation and mass production. The transition to a new model for supply chains will be underpinned by rapid digitalization.

Despite rapid advances in technology, the relationship between buyer and supplier is still largely paper-based. Digitizing the buyer-supplier relationship is fundamental to building a solid and time-saving supply chain. With technologies like artificial intelligence (AI) and the Internet of Things (IoT), supply chains can quickly switch to alternative suppliers when conventional suppliers experience disruption (Shen \& Li, 2017; Tagoe et al., 2005). The current crisis puts pressure on re-establishing a system that is already based on outdated processes, creating smart and agile supply chains, which are key to building a trade and investment network. the world can weather the "storms" of the future.

\subsection{Supply chain risk}

Supply Chain is the process of tracking goods through statistics and control from the supply chain, the replenishment of raw materials, to the retail stage, or in other words, the process of operating and managing the movement of goods (Carnovale et al., 2019). The trend towards just-in-time delivery, combined with attractive promotions to access the best sources, makes any supply chain fraught with risk. However, in Vietnam today, one of the most concerning issues in this field is the risk of supply chain disruption. Lee and Whang (2000) showed that supply chain risks include two groups: internal risks and external risks. However, this classification method is no longer suitable for today's context. Wang et al. (2014) have researched and shown that the overall risk of the supply chain includes supply risk, operational risk, demand risk, logistics risk, information risk and environmental risk. There is relatively little research on supply chain risk in Vietnam. The most prominent study is Nguyen et al. (2020), which divides supply chain risks into 6 main groups including: availability, cost and quality of human resources, legal issues, and level of trust. supplier reliability, raw material price fluctuations, and exchange rate fluctuations. Supply risks are understood as adverse results that affect the production and business situation of enterprises. Supply risk is one of the factors mentioned most often in research on risks in the supply chain. supply chains such as Jia et al. (2005). Operational risk is understood as the results and risks related to inefficiencies in the management and operation of companies participating in the supply chain. The company's internal activities such as changes in production processes, production capacity act as one of the causes of operational risks as well as risks in the export supply chain. Demand risk is the result of disruptions caused by the discrepancy between the company's forecasts and actual demand, affecting supply chain operations. Manufacturers are always trying to assume, measure, and estimate consumer demand as well as possible errors in predicting consumer needs (Gomm, 2010; Subramani, 2004). Logistics risks are understood as adverse outcomes that occur during the transportation, storage, and supply of goods between parts of the supply chain. Wang et al. (2009) indicated that the volatility and uncertainty occurring in the supply chain is believed to be one of the manifestations of the problem of ignoring logistical risks. Risks come from information asymmetry and misinformation leading to inefficient operation of supply chains and businesses in general. According to Chang et al. (2013), Chopra and Sodhi (2004); Nagati and Rebolledo (2013), possible communication risks between departments that can cause disruptions in the supply chain; Therefore, affecting the entire operation of the supply chain. Environmental risks are understood as events occurring due to the external environment (natural disasters, regulations, politics, etc.) that affect the operation of the entire system. Dani (2008) provided evidence on environmental risks, especially natural disasters, which affect the business performance of enterprises.

\subsection{Supply chain Effectiveness}

Manufacturers have long sought to improve performance indicators. However, the complexity and frequency of supply chains make it difficult to select appropriate supply chain effectiveness indicators. Few supply networks are functional and efficient, and many fail to monitor performance in crucial supply chain situations, which is a major mistake (Gunasekaran et al., 2004). Gunasekaran et al. (2004), developed a complete framework for supply chain effectiveness measurement that was classified into three categories: strategic, tactical, and operational processes.

\subsection{Supply chain resilience}

The spread of COVID-19 has caused serious delays in delivery of essential goods, while there is still other non-essential inventory in stock, which is not suitable for current demand. To improve supply chain operations, supply network managers 
must know what is happening and where, including current and expected threats from COVID-19, weather, and weather traffic events. Supply network resiliency (Singh \& Singh, 2019) powered by location information combines live spatial and business data in a common operational picture, to improve efficiency and reduce costly disruptions. Relationship theory was born affirming the importance of business relationships; is a solid theoretical basis for managers in researching, identifying, and developing competitive advantages of enterprises on the basis of building sustainable, mutually beneficial relationships. Inheriting the core foundations of resource-based theory. Relational theory identifies sustainable values of the enterprise accumulated from valuable resources, not easily changed or imitated, creating a difference of the enterprise when competing in the market. However, from the research perspective of the resource-based perspective, it ignores the fact that the enterprise exists as an independent unit in the economy, it is necessary to have exchanges and relationships to maintain operations business. In other words, the previous views do not explain how firms can gain competitive advantage from and in their relationships. Complementing this limitation of resource theory, complements and clarifies the benefits that businesses can derive from strategic and sustainable relationships. In fact, most businesses specialize in several areas, and it is difficult to have all the necessary resources at the same time. This requires businesses to exchange information and resources with other parties in the market. This exchange contains unwanted risks, and to minimize these uncertainties, businesses often seek and build deep and lasting relationships, to get rid of constraints or disadvantages. of the market mechanism. Competitive advantage is understood as the advantages that not only help an enterprise make a remarkable difference compared to competitors in the same industry, but also affirm the long-term existence and development of the business in the face of constant fluctuations of the business environment. To obtain a sustainable competitive advantage, Porter (1990) pointed out that firms must possess one of two advantages: low cost or differentiation, based on valuable, scarce, non-easily available resources. easily replaced or imitated by competitors. Assume businesses operate in free-market relationships, where buyers and sellers freely transact according to market mechanisms, with no significant values to generate profits will easily imitate, replace and turn those values into their resources. At that time, to ensure its interests, enterprises must establish profitable relationships with a chain or pair of partners in the market, forming a competitive advantage for mutual ownership and benefit. Relational returns are associated with the concept of "super profit" generated from a specific exchange relationship between partners who are allies (Punniyamoorthy et al., 2019).

\section{Research Methods}

\subsection{Context and sample}

The relationship between businesses in the supply chain is still problematic. SMEs account for $98 \%$ of enterprises in Vietnam, but only $21 \%$ of these enterprises are linked to foreign supply chains. This rate is lower than many countries in the ASEAN region such as Thailand (30\%), Malaysia (46\%). Up to now, the number of Vietnamese companies in the supporting industry that are qualified to participate in the supply chain is still too small, SMEs in Vietnam mainly have a relationship of buying and selling goods with each other, not focusing on supporting according to the supply chain. In the context that foreign direct investment (FDI) enterprises dominate many products supply chains, due to a lack of capital, Vietnamese SMEs have not properly invested in technological innovation. The structure of enterprises is still not reasonable, for example, industries such as textiles and garments, leather and footwear do not have a synchronous structure. The reality is that Vietnam is standing at the bottom of the global supply chain and has stood there for nearly a quarter of a century. The Bank's operations have not been standardized according to international standards and are still heavily dependent on the state. This service is new, contains many risks and banks do not have much experience to implement. The ability to raise capital of the financing capacity also depends on the bank's own capital. Therefore, if the enterprise participating in the supply chain has a large capital need, while the capital source of the bank is small, it will not satisfy the requirements of the business. In addition, supply chain financing of commercial banks is associated with foreign currency capital. Therefore, how to mobilize enough foreign currency to meet the borrowing needs of enterprises participating in the supply chain is a big problem for many commercial banks. High operating costs, high technology has not been applied to connect foreign-invested enterprises and domestic enterprises. New banks can only apply simple technologies, only serving the surface problems. High technologies such as block chain, serving directly to SCF have not been implemented yet. E-commerce - Following the current trend of Vietnam's economy shifting to online sales from offline platforms, banks have a huge opportunity to finance SCF for companies. Online Platform/Automation - Digitization can provide great leverage in terms of both integration and information flow for the Bank and other stakeholders. Potential Industries - Focus on untapped or untapped industries such as Commodities, Electrical \& Electronics, Consumer Goods, FMCG and agriculture-based industries to finance your supply chain surname. In the past few years, financial support for supply chains has become more and more popular due to globalization and more complex supply chains, especially in industries such as automobiles, manufacturing, and retail sector. Supply chain financing is a new approach of the bank in providing financial support to businesses with a win-win perspective. In Vietnam, supply chain support services have appeared, but have not yet made a clear mark. Service packages to support distributors are often implicitly understood as credit loans with strict conditions. However, until now, credit has hardly grown, forcing banks to specialize more in their products if they want to maintain growth momentum (Flynn et al., 2010).

Small and medium enterprises enjoy a lot of support from the Government. There are 8 types of support that small and medium enterprises will naturally receive from the State. These are: Credit access support, credit guarantee fund for small and medium enterprises; tax and accounting support; support production premises; technology support; support incubators. technical facilities, common working areas; support market expansion; informational, advisory and legal support; support 
human resource development. In addition, small and medium enterprises converted from household businesses; innovative start-up small and medium enterprises; Small and medium-sized enterprises participating in industry clusters and value chains will enjoy more support from the state. Innovative start-up small and medium-sized enterprises and small and medium-sized enterprises participating in industrial clusters and value chains will be loaned and financed by the small and medium-sized enterprise development fund established by the Prime Minister. To study the influence of supply chain finance in global supply chains, we conducted a survey of 2000 small and medium-sized enterprises that received financial support in different forms according to convenience sampling rules. After a period of 3 months from the time of the survey to the time of data collection, we collected all 938 survey questionnaires. After that, we screened and entered the data, the results were 890 valid questionnaires to conduct analysis and test the research hypotheses.

\subsection{Research models}

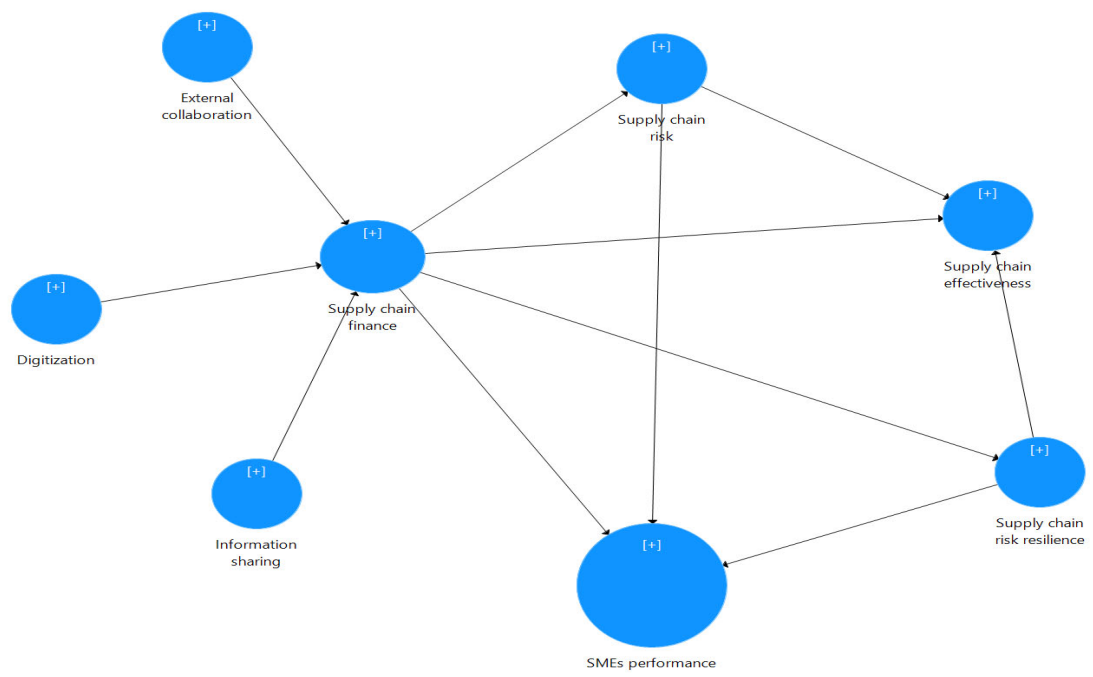

Fig. 1. Research model (Martin \& Hofmann, 2019)

Inside:

The information sharing scale was adapted from Bowersox et al. (2000), with 1 representing "strongly disagree" and 5 representing "strongly agree".

Information sharing (IF)

IS1: Companies utilize information sharing to share relevant information

IS2: Firms reap greater benefits because of information exchange.

IS3: Information sharing facilitates collaboration among enterprises in the supply chain.

Dyer and Singh (1998) developed a scale for external collaboration that ranged from 1 to 5 , with 1 being strongly disagree and 5 being highly agreed.

External Collaboration (EC)

EC1: Predictions about demand.

EC2: Inventory management policy.

EC3: There is a change in price.

EC4: Disruption in the supply chain.

The SCE scale was developed from Fugate et al. (2009), with 1 representing "strongly disagree" and 5 representing "strongly agree".

Supply chain effectiveness (SCE)

SCE1: The expense of transportation.

SCE2: The cost of warehousing. 
SCE3 is the cost of inventory.

The digitization was based from Caniato et al. (2016), where 1 represents "strongly disagree" and 5 represents "strongly agree."

Dictaphones are being replaced by computers (DIG)

Dig1: Introduces innovative methods of involving buyers and suppliers.

Dig2: It assists in the upgrading of buyer and supplier business.

Dig3: It is in the interaction between buyers and suppliers that the solution lies.

SCF was adapted from (Zhang, 2015), with 1 representing "strongly disagree" and 5 representing "strongly agree."

Supply chain finance is a term that is used to describe the financing of a supply chain (SCF)

SCF1: You consider SCF to be a risk mitigation method.

SCF2: SCF increases the amount of working capital available.

SCF3: SCF delivers a high level of total supply chain efficiency, which is referred to as SCF3.

SCF4: SCF categorizes this as a high-risk preventative strategy.

The SCR scale was adapted from Phan et al. (2020), with 1 representing "strongly disagree" and 5 representing "strongly agree."

Supply chain risk (SCR)

SCR1: We keep an eye on our suppliers for signs of potential SCR on a regular basis.

SCR2: We exclusively distribute our products to markets that we are intimately familiar with.

SCR3: In order to mitigate SCR, we maintain additional inventory and capacity buffers.

\subsection{Analytical techniques}

For the initial data entering, we make use of the Excel 2020 software. Then, we utilized the Smart PLS 3.3.6 software to assess the reliability of the scale and conduct an EFA - exploratory factor analysis - to further investigate the data. The CFA - confirmatory factor analysis software is used to test overall reliability, discriminant validity, indications of the measurement model, and lastly the structural model is evaluated to test the study hypotheses.

The number of research that have used PLS-SEM that have been published in recent years has increased dramatically, according to Hair et al (2014). Because PLS-SEM offers numerous advantages over CB-SEM in the following situations: organizational behavior, information system management, strategic management, and marketing research, PLS-SEM is increasingly being used in these fields: The following characteristics are acceptable: (1) limited sample size; (2) data that is not normally distributed. Complex research models with multiple intermediate, regulatory, latent, and observable variables can be used. (3) Capable of examining the structure of the result model (Reflective) and the cause model (Formative); (4) Appropriate for predictive-oriented investigations; (Marucheck et al., 2011; Henseler et al., 2015).

Furthermore, if non-normally distributed data is a significant issue for CB-SEM, it is important to note that (ie: CB-SEM requires normally distributed data, this is said to be very difficult since studies often survey by non-probability convenience method). When dealing with data that is not typically distributed, PLS-SEM is "very powerful" (Hair et al., 2013).

If you are utilizing the PLS-SEM technique, according to Hair et al. (2013) and Chin (2010), you must perform two steps: first, validate the results. (1) Verify the measurement model; and (2) Verify the structural model, where appropriate. The following is an example:

(1) An evaluation of the measurement model is performed.

the consistency of the indicator variables; (or called observed variables)

In the result model (Reflective model), the indicator variables are explained by the latent variable, and the load factor of the indicator variables is more than 0.7 (or 0.40 for exploratory research) (Hair et al., 2012).

- Consistent reliability on an intrinsic level 
Cronbach's alpha value (Henseler et al., 2015; Tomlinson, 2011) is used to assess intrinsic consistency reliability, with an acceptable value of 0.7 in the first study periods. Each latent variable must be accompanied by at least two indicator variables, according to the authors.

- The value of convergence

The value of convergence assesses the link between indicators that measure the same latent variable in different ways. AVE (Average variance extracted, reflecting the overall variability of observed variables calculated by latent variable analysis) is a measure of the scale's convergence value. For exploratory studies, the composite confidence coefficient (CR) should be between 0.6 and 0.7 , but ideally should be less than 0.7 ; the external load coefficient of the observed variables should be less than 0.708; and the average variance extracted (AVE) should be less than 0.70 . Using discriminant validity to guarantee that there is no association between the factors used to test the components, discriminant validity can be measured. The discriminant value of a measurement model is an important criterion in the analysis of measurement models. It assesses the degree to which concepts in the research model are distinguishable from one another (Henseler et al., 2015). When considering discriminant validity, there are two levels to consider: the degree of distinction between components within the same concept (within construct, if it is a concept of level 2 or higher); the degree of distinction between components across different concepts (cross construct, if it is a concept of level 2 or higher), or it refers to the critical measurement model (saturated model, the concepts in the research model are free to relate to each other). When the value of the criterion HTMT (Heterotrait - Monotrait) is less than 0.85 (Henseler et al., 2015), or when the square root AVE of each measure is more than the system, the discriminant value is eligible. The correlations between that factor and other factors are represented by latent variables. As an additional consideration while evaluating the measurement model, it is required to consider the multicollinearity of the indicator variables (a VIF value of 5 indicates that there is no multicollinearity). For Henseler and colleagues (2015), the following coefficients must be satisfied before it is possible to infer that the model accurately represents market data (the "goodness of model fit"). If the exploratory research type can accept less than 0.12, the coefficient SRMR (standardized root mean square residual) should be less than 0.082; the coefficient d ULS should be less than 95 percent; the coefficient d G1 should be less than 95 percent; and the coefficient d G2 should be less than 95 percent.

(2) Observation and evaluation of the structural model

After performing the PLS-SEM analysis, the second step is to evaluate the structural model using the Bootstrapping method with a sample size of 5000. (return-sampling). In the opinion of Hair et al. (2012b), potential markers for the evaluation of structural models include the following:

1) The R2 coefficient, which is used to determine the variation of the model.

2) Impact (intensity) of the degree (f2) of influence

In addition to the $t$ values and confidence intervals, the influence factor $(ß)$ comprises the following:

- The model's variation is determined by the coefficient of determination. (R2 is the coefficient of determination.)

The R2 value is defined as the percentage of variation in endogenous variables that can be explained by exogenous variables in a regression model (Hair et al. 2014). The R2 value is a number that varies from 0 to 1 . The closer the $\mathrm{R} 2$ value is to one, the better the model's fit to the data set is considered. The closer R2 is to zero, the less appropriate the model is considered to be. Consequently, R2 values are important indications of the link between latent variables in a model and are the primary criterion used to assess the effectiveness of a structural model (Hair et al., 2014). According to Henseler et al. (2015), the acceptable level of 2 varies depending on the setting of the investigation. However, the following ratings are still provided for reference: strong (0.67), moderate (0.33), and weak (0.15). (0.19).

- The degree of influence (also known as the effect size, f2).

Also, according to Henseler et al. (2015), in order to take into account the impact of exogenous variables on endogenous variables, the influence coefficient $\mathrm{f} 2$ must be evaluated. When $\mathrm{f} 2$ is at 0.02 levels, 0.15 levels, and 0.35 levels, it is possible to conclude that the influence level is weak, fair, or strong, depending on the situation.

- Estimates of the path coefficients

Exogenous variables and endogenous variables are related by a coefficient of influence (ß), which offers information about the strength of the relationship between the variables. $\beta$ also reflects the direction of relationship (either positive or negative) between the ideas in the study model (Henseler et al., 2015; Lu et al., 2020), which corresponds to the hypothesized direction in the literature. The Bootstrapping approach is proposed to determine the significance of the relationship between the two variables (Hair et al., 2014). To determine the accuracy of the PLS estimates, the Bootstrapping approach employs resampled sampling $(\mathrm{n}=5000)$ in place of sampling from the original data set, and it is described in detail below (Hair et al. 2014). The findings of the t-statistic can be used to decide the level of statistical significance to be applied (p-value). Thus, the statistical value $\mathrm{t}=1.6497$ corresponds to a level of confidence equal to $90 \% ; \mathrm{t}=1.9676$ corresponds to a level of confidence equal to $95 \% ; \mathrm{t}=2.5916$ corresponds to a level of confidence equal to 99 percent. 


\section{Research results}

The results of testing the reliability of the scale on Smart PLS 3.3.6 software are performed by PLS technique. The results show that all variables satisfy the reliability and validity of the scale. With the following results:

Table 1

Construct Reliability and Validity

\begin{tabular}{|c|c|c|c|c|}
\hline & Cronbach's Alpha & rho_A & Composite Reliability & Average Variance Extracted (AVE) \\
\hline Digitization & 0.893 & 0.893 & 0.892 & 0.675 \\
\hline External collaboration & 0.881 & 0.897 & 0.885 & 0.721 \\
\hline Information sharing & 0.848 & 0.858 & 0.846 & 0.583 \\
\hline SMEs performance & 0.898 & 0.902 & 0.898 & 0.689 \\
\hline Supply chain effectiveness & 0.926 & 0.943 & 0.925 & 0.758 \\
\hline Supply chain finance & 0.875 & 0.877 & 0.874 & 0.634 \\
\hline Supply chain risk & 0.912 & 0.958 & 0.904 & 0.715 \\
\hline Supply chain risk resilience & 0.906 & 0.916 & 0.906 & 0.621 \\
\hline
\end{tabular}

The variables in the research model all satisfy the values of Cronbach Alpha, the total correlation coefficient, Composite reliability and Average Variance Extracted according to the guidance of Hair et al. $(2011 ; 2014 ; 2017)$ and Henseler et al. $(2009 ; 2015)$. The test results of discriminant validity of latent variables are as follows:

Table 2

Discriminant Validity (Fornell-Larcker Criterion)

\begin{tabular}{|c|c|c|c|c|c|c|c|c|}
\hline & Digitization & $\begin{array}{c}\text { External } \\
\text { collaboration }\end{array}$ & $\begin{array}{l}\text { Information } \\
\text { sharing }\end{array}$ & $\begin{array}{c}\text { SMEs } \\
\text { performance }\end{array}$ & $\begin{array}{l}\text { Supply chain } \\
\text { effectiveness }\end{array}$ & $\begin{array}{l}\text { Supply chain } \\
\text { finance }\end{array}$ & $\begin{array}{l}\text { Supply } \\
\text { chain risk }\end{array}$ & $\begin{array}{l}\text { Supply chain risk } \\
\text { resilience }\end{array}$ \\
\hline Digitization & 0.821 & & & & & & & \\
\hline External & 0.585 & 0.849 & & & & & & \\
\hline Information & 0.135 & 0.247 & 0.763 & & & & & \\
\hline SMEs performance & 0.385 & 0.494 & 0.308 & 0.830 & & & & \\
\hline Supply chain & 0.186 & 0.296 & 0.074 & 0.137 & 0.871 & & & \\
\hline Supply chain & 0.705 & 0.620 & 0.222 & 0.507 & 0.198 & 0.796 & & \\
\hline Supply chain risk & -0.145 & -0.223 & -0.352 & -0.229 & 0.177 & -0.140 & 0.846 & \\
\hline Supply chain risk & -0.286 & -0.316 & -0.297 & -0.424 & 0.127 & -0.367 & 0.286 & 0.788 \\
\hline
\end{tabular}

The results in Table 3 show that all values on the diagonal are larger than the values outside the diagonal, specifically the smallest value on the diagonal is 0.763 is still larger than the largest value outside the diagonal is 0.705 so means that the research variables ensure the discriminant validity and the convergent validity, satisfying to perform the next tests in the evaluation of the measurement and structural models under the guidance of Chin (2010); Hair et al. (2011, 2014, 2017).

Table 3

The results of R-square

\begin{tabular}{lll} 
& & \\
\hline SMEs performance & R Square & R Square Adjusted \\
Supply chain effectiveness & 0.358 & 0.354 \\
Supply chain finance & 0.410 & 0.403 \\
Supply chain risk & 0.569 & 0.565 \\
Supply chain risk resilience & 0.020 & 0.017 \\
\hline
\end{tabular}

The R-square results show that the variables in the model explain a lot for Supply chain finance up to nearly $60 \%$. At the same time, the role of supply chain management also explains a lot for SMEs performance in the context of the current pandemic with the variation of SMEs performance being explained about $40 \%$. The variables in the research model also explain nearly $50 \%$ of the variation in supply chain performance of small and medium enterprises in the current global supply chain context. The final step of the measurement model evaluation is that we evaluate the F-square coefficient (See Table 4).

Table 4

The results of F-Square values

\begin{tabular}{|c|c|c|c|c|c|c|c|c|}
\hline & Digitization & $\begin{array}{c}\text { External } \\
\text { collaboration }\end{array}$ & $\begin{array}{c}\text { Information } \\
\text { sharing }\end{array}$ & $\begin{array}{c}\text { SMEs } \\
\text { performance }\end{array}$ & $\begin{array}{l}\text { Supply chain } \\
\text { effectiveness }\end{array}$ & $\begin{array}{c}\text { Supply chain } \\
\text { finance }\end{array}$ & $\begin{array}{c}\text { Supply } \\
\text { chain risk }\end{array}$ & $\begin{array}{l}\text { Supply chain risk } \\
\text { resilience }\end{array}$ \\
\hline Digitization & & & & & & 0.415 & & \\
\hline External & & & & & & 0.311 & & \\
\hline Information & & & & & & 0.322 & & \\
\hline \multicolumn{9}{|l|}{ SMEs performance } \\
\hline Supply chain & & & & 0.323 & & & & \\
\hline Supply chain & & & & 0.256 & 0.223 & & 0.301 & 0.156 \\
\hline Supply chain risk & & & & & 0.267 & & & \\
\hline Supply chain risk & & & & & 0.300 & & & \\
\hline
\end{tabular}


The results of the f-square test show that the latent variables are strongly associated with each other and are very convenient to test the structural model and research hypotheses. The results of testing the research hypotheses are as follows,

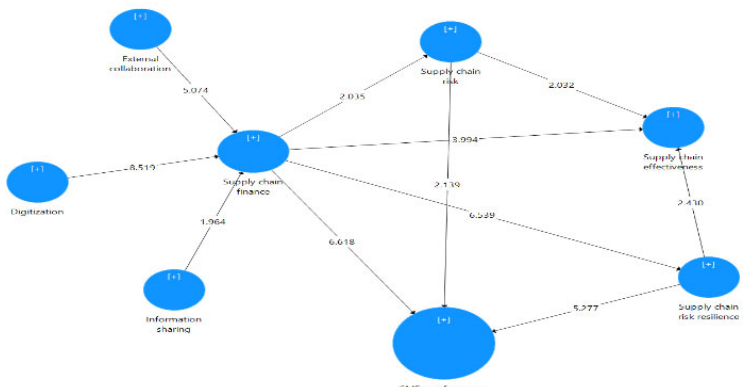

Fig. 2. PLS system after removing the variable Financial Institutions

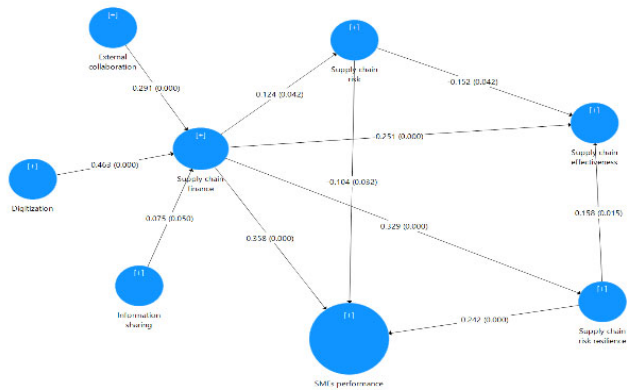

Fig. 3. Hypothesis test results

From the test results, External Collaboration; Digitization and Information sharing both have a positive impact on supply chain finance with respective impact coefficients of $0.291 ; 0.463$ and 0.705 at the significance level of $1 \%(\mathrm{P}-\mathrm{value}=0.000)$ and Information sharing alone is at the significance level of $5 \%(\mathrm{P}$-value $=0.050)$. This means that supply chain finance is made up of 3 factors of external cooperation, digital and information sharing of enterprises. When businesses have good cooperation with external partners, namely suppliers, customers, banks, investors, the ability to access financial resources will be easier and the ability to be financed will be easier. supply chain support would be better. In the context of the current Covid-19 pandemic, the risk of supply chain disruption is huge. Supply chain risks are not only stopped by the epidemic, but also by the supply side and the demand side. According to the research team's expectation, thanks to supply chain funding will reduce risks in the supply chain. Therefore, the impact of supply chain finance on supply chain risk will be opposite. Indeed, the surveyed data coincided with the resource-based theory, the dynamic capacity theory of enterprises. The results show that supply chain finance has a negative effect on supply chain risk with an impact coefficient of 0.124 at the $5 \%$ significance level $(\mathrm{P}$-value $=0.042$ ). Thanks to supply chain financing activities, businesses can better withstand supply chain risks and operate better. Specifically, supply chain finance has a strong impact on SMEs performance with an impact coefficient of 0.358 at the $1 \%$ significance level $\left(\mathrm{P}_{-}\right.$value $\left.=0.000\right)$. In contrast to supply chain finance that has a positive effect on SME performance and Supply chain effectiveness, supply chain risk has a negative impact on SME performance and supply chain effectiveness with coefficients of 0.104 and 0.152 respectively at the $5 \%$ significance level. $P_{-}$value $<0.05$ ). This is completely in line with reality and is easy to understand. Supply chain risks can disrupt business operations, may lose orders due to the impact of covid or due to changes in customer demand. Or the supplier does not provide enough raw materials for production. Therefore, supply chain risks reduce the operational efficiency of enterprises and even affect their ability to continue as a going concern. Finally, we are interested in the role of supply chain risk resilience (Linnenluecke, 2017) in the global supply chain of small and medium enterprises in Vietnam in the context of the current Covid-19 pandemic. The Bootstrapping test results show that supply chain finance has a positive impact with statistical significance with a very strong impact on supply chain risk resilience with an impact coefficient of 0.329 at $1 \%$ significance level $(\mathrm{P}$ value $=0.000)$. At the same time, supply chain risk resilience also has a positive impact on supply chain effectiveness and SMEs performance with the respective impact coefficients of 0.158 and 0.242 at the significance level of $5 \%\left(\mathrm{P}_{-}\right.$value $\left.=0.015\right)$ and $1 \%(\mathrm{P}-$ value $) .0 .0000)$. The more small and medium-sized enterprises in Vietnam have activities to combat supply chain risks, the better the ability to recover and improve business performance. Next, we determine the impact of supply chain finance on SMEs performance without supply chain effectiveness with the following model:

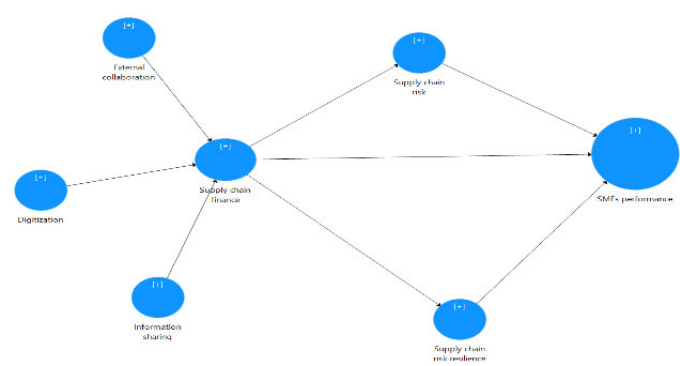

Fig. 4. Impact of supply chain finance on SMEs performance

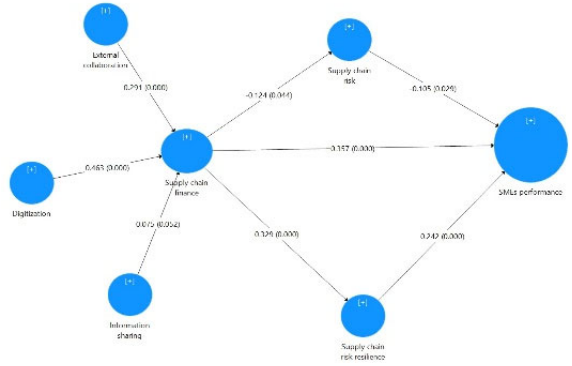

Fig. 5. Impact of supply chain finance on SMEs performance 
The results show that when supply chain effectiveness is not considered, supply chain finance still has a statistically significant impact on SME performance, supply chain risk resilience with coefficients of 0.357 and 0.329 respectively at the significant level 1\%. Besides, supply chain finance still has a negative impact on supply chain risk. We again review the role of supply chain finance to supply chain effectiveness with the following model:

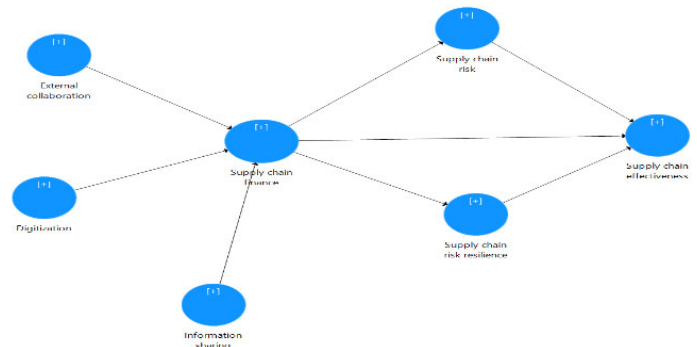

Fig. 6. Supply chain finance and supply chain effectiveness

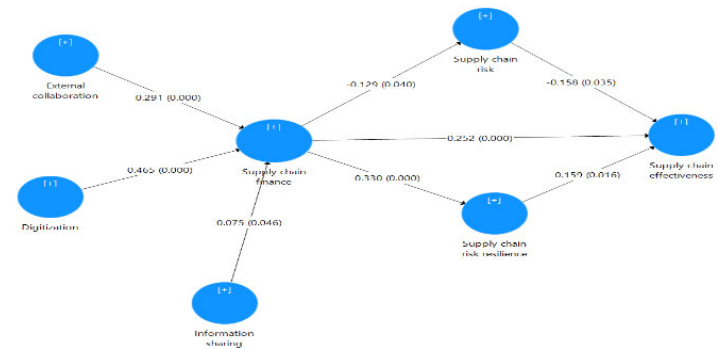

Fig.7. Impact of supply chain finance on supply chain effectiveness

The results show that in this model, supply chain finance affects supply chain effectiveness with a coefficient of 0.252 at the $1 \%$ significance level. That means that in all cases supply chain finance still has a strong impact on supply chain effectiveness. To test the role of supply chain risk resilience, we test the following model:

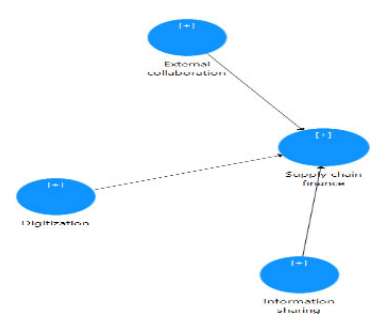

Fig. 8. Supply chain risk resilience

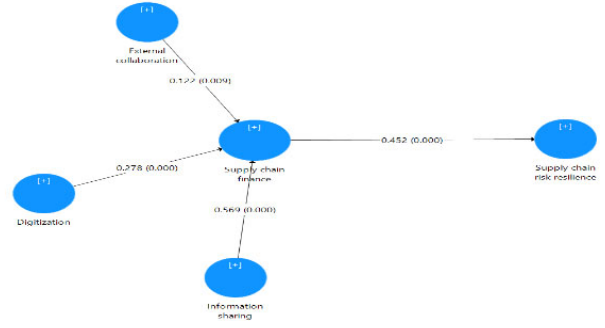

Fig. 8. Impact of supply chain finance on supply chain risk resilience

The results show that when looking directly at the impact of supply chain finance on supply chain risk resilience, supply chain finance has a very large role in supply chain risk resilience with a very strong impact coefficient of 0.452 at $1 \%$ significance level. $\left(\mathrm{P}_{-}\right.$value $\left.=0.000\right)$. The results of the research hypotheses are summarized as follows:

Table 5

Path Coefficients

\begin{tabular}{|c|c|c|c|c|c|}
\hline & $\begin{array}{c}\text { Original } \\
\text { Sample (O) }\end{array}$ & $\begin{array}{c}\text { Sample } \\
\text { Mean (M) }\end{array}$ & $\begin{array}{c}\text { Standard Deviation } \\
\text { (STDEV) }\end{array}$ & $\begin{array}{l}\text { T Statistics } \\
(|\mathrm{O} / \mathrm{STDEV}|)\end{array}$ & $\begin{array}{c}\mathbf{P} \\
\text { Values }\end{array}$ \\
\hline Digitization $\rightarrow$ Supply chain finance & 0.463 & 0.463 & 0.054 & 8.519 & 0.000 \\
\hline External collaboration $\rightarrow$ Supply chain finance & 0.291 & 0.292 & 0.057 & 5.074 & 0.000 \\
\hline Information sharing $\rightarrow$ Supply chain finance & 0.075 & 0.078 & 0.038 & 1.964 & 0.05 \\
\hline Supply chain finance $\rightarrow$ SMEs performance & 0.358 & 0.356 & 0.054 & 6.618 & .0000 \\
\hline Supply chain finance $\rightarrow$ Supply chain effectiveness & 0.251 & 0.256 & 0.063 & 3.994 & 0.000 \\
\hline Supply chain finance $\rightarrow$ Supply chain risk & 0.124 & -0.128 & 0.061 & 2.035 & 0.042 \\
\hline Supply chain finance $\rightarrow$ Supply chain risk resilience & 0.329 & -0.331 & 0.05 & 6.539 & 0.000 \\
\hline Supply chain risk $\rightarrow$ SMEs performance & -0.104 & -0.107 & 0.049 & 2.139 & $\mathbf{0 . 0 3 2}$ \\
\hline Supply chain risk $\rightarrow$ Supply chain effectiveness & -0.152 & 0.151 & 0.075 & 2.032 & 0.042 \\
\hline Supply chain risk resilience $\rightarrow$ SMEs performance & -0.242 & -0.246 & 0.046 & 5.277 & 0.000 \\
\hline Supply chain risk resilience $\rightarrow$ Supply chain effectiveness & -0.158 & 0.161 & 0.065 & 2.43 & 0.015 \\
\hline
\end{tabular}

\section{Conclusion}

Recent statistics show that the impact of Covid-19 has caused economic distress in countries, reduced global trade, in which major economies such as the US, China, and Europe are also reeling from the crisis. panic. Diversification of supply and the application of digital platforms is seen as the key to building a smart and sustainable supply chain, ensuring a long-term recovery after the pandemic. The current supply chain is the environment for business investment, knowledge, experience, 
technology solutions in the digitization of trade finance and supply chains in the region, as well as the global market. The relationship between enterprises in the supply chain still has many issues that need to be resolved to support them to better participate in the chain. We need to learn more from strong economies in the world, draw lessons from real case studies and apply them appropriately to the Vietnamese market. Boeing's supply chain management model is considered a rewarding experience for businesses. In addition to establishing partnerships with good suppliers, since 1998, the company has built its own system of ranking the performance of suppliers on a global scale based on the expectations of customers. Quality, ontime delivery and business management. The system has given the company more control over the performance of its suppliers across four different management teams, while providing feedback. valuable to suppliers. The big difficulty of Vietnam is that it needs the consensus of ministries, sectors and many participating units in a synchronous manner to create favorable conditions for the development of the supply chain financial financing market. In particular, the challenge is how to create profits by reducing operating costs, applying technology to connect foreign direct investment enterprises with small and medium enterprises. In addition, the market is increasingly volatile and risky. In fact, in Vietnam, businesses often focus on their business performance, but pay little attention to partners in the supply chain. Meanwhile, many corporations in more developed economies, such as Korea or Japan, enjoy great success by supporting their supply chain partners. The cost to deploy technology platforms for supply chain control is quite large for each banking unit. Meanwhile, the slow amount of capital attraction requires sponsors to persevere in implementing each small item. Therefore, in order for domestic commercial banks to increase investment activities in supply chains, ministries, branches and localities must encourage all businesses to work together to manage supply chains more smoothly. In particular, issues related to financial transparency for supply chain participants also need to be standardized, in order to limit risks and increase unsecured loans based on cash flow management.

\section{Solutions to promote Vietnamese SMEs to participate in the global value chain by supply chain finance}

Firstly, Vietnamese SMEs need to improve to increase their global competitiveness such as meeting international standards of quality and sector; strengthen commercial capacity, governance and connectivity. At the same time, look for opportunities from the global market and opportunities from the domestic market.

Second, research and select products to participate in value chain development in accordance with Vietnam's competitiveness, large market capacity, potential and commitment to the orientation of leading companies in global supply chain.

Third, the State needs to create more favorable conditions and support businesses, especially in terms of capital so that businesses have the opportunity to participate in the supply chain. In which, SMEs have more favorable access to credit; Connecting SMEs to participate in the production chains of multinational corporations and global partner enterprises; Strengthen connectivity in existing value chains by implementing more activities upstream and downstream.

Fourthly, deploying forecasting activities, providing information on technology and standards of markets, thereby, helping businesses accurately assess information, market opportunities, competition of parties and necessary action with each product group in the country to further improve the production process, move up the ladder in the global supply chain.

Fifth, the State needs to create more favorable conditions in terms of mechanisms and policies for Vietnamese SMEs to grow, innovate technology and product designs, bring Vietnamese SMEs into the global value chain, and promote innovation and productivity improvement process of Vietnamese SMEs.

In addition, the Government needs to have support for small and medium enterprises to participate in production and supply chains. That support is the credit system, infrastructure, administrative procedures... Ministries and functions need to strengthen the connection of enterprises participating in the chain, update opportunities and challenges from trade conflicts. global, export support services such as insurance, goods inspection, logistics, business information, etc. Currently, many countries and governments have participated in the supply chain finance market, in order to improve the competitiveness of the domestic supply chain, especially to create conditions for small and medium enterprises to participate in the market. global supply chain. In addition, some countries are concerned about money flowing into the virtual economy such as investment in real estate, securities, etc., so promoting the supply chain financial financing market is also a solution to boost capital inflows. production and business activities, contributing to economic growth. For Vietnam, supply chain financing is also an important market that requires specific initiatives and policies to promote this activity. In particular, the government needs to issue specific regulations and guidelines to create a legal basis for entities such as banks or many economic sectors participating in supply chain financing. From a banking perspective, the supply chain finance market in Vietnam is still modest, so solutions are needed to promote this activity, especially focusing on small and medium enterprises. In particular, the challenge is how to create profits by reducing operating costs, applying technology to connect foreign direct investment enterprises with small and medium enterprises. In addition, the market is increasingly volatile and risky, so not only the banking system but also the government and ministries and sectors need training programs, capacity building and support for businesses to have financial records. with the guarantee of the authorities to create trust for partners. In particular, if 
businesses, banks and state management agencies have good connections, the supply chain financial financing market will be favorable and support products will be diversified.

In the Asia - Pacific region; including Vietnam, several types of e-finance platforms have proven valuable to strengthen linkages between supply chain members and increase their ability to attract financial service providers. This is a trend that will create a driving force to support the development of enterprises to achieve the quantity and improve the quality of enterprises according to the goals set by the Government of Vietnam in the next few years. To improve self-healing, businesses need to understand their assets, figure out which elements of supply chain operations can respond to drastic changes in demand or can be reused for different purposes (e.g. flexible assets, process automation, labor practices, etc.); From there, apply it to enhance the resilience of the business in the future, such as investing in operational analysis systems, digitizing production and improving the ability to analyze scenarios based on data. available. At the same time, enterprises need to explore and take advantage of opportunities for automation (process automation, modernization of production stages, etc.), through the vision built for the zero-based supply chain to Make informed investment choices. In addition, businesses also need to balance short-term values with long-term stable needs, such as building a digital factory, or using robots for warehouses. Finally, enterprises can deploy the "control tower" model as part of their capacity, to create the ability to control and closely monitor to ensure a balance between the two factors: products that meet standards for customers - safety of the entire supply chain and value for shareholders. To be ready for all uncertainties in the future, businesses now need to improve their research, forecasting, and scenario development capabilities; Anticipate fluctuating patterns of demand in the market and enhance control - intelligent monitoring. In addition, businesses need to rethink costs, rethink routine expenses when placed in the new context of the post-Covid-19 world, and study and build models of costs that bring about benefits. worthy investment. Simultaneously, gradually establishing a digital technology application ecosystem, reducing tangible assets, allowing flexible variable cost structure as required.

\section{References}

Ali, Z., Gongbing, B., \& Mehreen, A. (2020). Does supply chain finance improve SMEs performance? The moderating role of trade digitization. Business Process Management Journal, 26(1), 150-167.

Baihaqi, I., \& Sohal, A. S. (2013). The impact of information sharing in supply chains on organisational performance: an empirical study. Production Planning \& Control, 24(8-9), 743-758.

Camerinelli, E. (2009). Supply chain finance. Journal of Payments Strategy \& Systems, 3(2), 114-128.

Caniato, F., Gelsomino, L. M., Perego, A., \& Ronchi, S. (2016). Does finance solve the supply chain financing problem?, Supply Chain Management: An International Journal, 21(5), 534-549.

Carnovale, S., Rogers, D. S., \& Yeniyurt, S. (2019). Broadening the perspective of supply chain finance: The performance impacts of network power and cohesion. Journal of Purchasing and Supply Management, 25(2), 134-145.

Chin, W. W. (2010). How to write up and report PLS analyses. In Handbook of partial least squares (pp. 655-690). Springer, Berlin, Heidelberg.

Chang, S., Gong, Y., Way, S. A., \& Jia, L. (2013). Flexibility-oriented HRM systems, absorptive capacity, and market responsiveness and firm innovativeness. Journal of Management, 39(7), 1924-1951.

Chopra, S., \& Sodhi, M. S. (2004). Supply-chain breakdown. MIT Sloan Management Review, 46(1), 53-61.

Dubey, R., Gunasekaran, A., Childe, S. J., Papadopoulos, T., Blome, C., \& Luo, Z. (2017). Antecedents of resilient supply chains: An empirical study. IEEE Transactions on Engineering Management, 66(1), 8-19.

Frohlich, M. T., \& Westbrook, R. (2001). Arcs of integration: an international study of supply chain strategies. Journal of operations management, 19(2), 185-200.

Flynn, B. B., Huo, B., \& Zhao, X. (2010). The impact of supply chain integration on performance: A contingency and configuration approach. Journal of Operations Management, 28(1), 58-71.

Gomm, M. L. (2010). Supply chain finance: applying finance theory to supply chain management to enhance finance in supply chains. International Journal of Logistics: Research and Applications, 13(2), 133-142.

Garrett, R. P., Covin, J. G., \& Slevin, D. P. (2009). Market responsiveness, top management risk taking, and the role of strategic learning as determinants of market pioneering. Journal of Business Research, 62(8), 782-788.

Hair, J. F., Ringle, C. M., \& Sarstedt, M. (2011). PLS-SEM: Indeed a silver bullet. Journal of Marketing theory and Practice, 19(2), 139152.

Hair Jr, J. F., Hult, G. T. M., Ringle, C. M., \& Sarstedt, M. (2021). A primer on partial least squares structural equation modeling (PLSSEM). Sage publications.

Hair, J. F., Henseler, J., Dijkstra, T. K., \& Sarstedt, M. (2014). Common beliefs and reality about partial least squares: comments on Rönkkö and Evermann.

Hair Jr, J. F., Sarstedt, M., Ringle, C. M., \& Gudergan, S. P. (2017). Advanced issues in partial least squares structural equation modeling. saGe publications.

Henseler, J., Ringle, C. M., \& Sarstedt, M. (2015). A new criterion for assessing discriminant validity in variance-based structural equation modeling. Journal of the academy of marketing science, 43(1), 115-135.

Henseler, J., Ringle, C. M., \& Sinkovics, R. R. (2009). The use of partial least squares path modeling in international marketing. In New challenges to international marketing. Emerald Group Publishing Limited.

Martin, J., \& Hofmann, E. (2019). Towards a framework for supply chain finance for the supply side. Journal of Purchasing and Supply Management, 25(2), 157-171.

Le, T., Nguyen, T., Phan, T., Tran, M., Phung, X., Tran, T., \& Giao, K. (2019). Impact of corporate social responsibility on supply chain management and financial performance in Vietnamese garment and textile firms. Uncertain Supply Chain Management, 7(4), 679-690.

Lee, H. L., \& Whang, S. (2000). Information sharing in a supply chain. International journal of manufacturing technology and management, 1(1), 79-93. 
Linnenluecke, M. K. (2017). Resilience in business and management research: A review of influential publications and a research agenda. International Journal of Management Reviews, 19(1), 4-30.

Li, H., Mai, L., Zhang, W., \& Tian, X. (2019). Optimizing the credit term decisions in supply chain finance. Journal of Purchasing and Supply Management, 25(2), 146-156.

Li, S., \& Chen, X. (2019). The role of supply chain finance in third-party logistics industry: a case study from China. International journal of logistics research and applications, 22(2), 154-171.

Lu, Q., Liu, B., \& Song, H. (2020). How can SMEs acquire supply chain financing: The capabilities and information perspective, Industrial Management \& Data Systems, $120(4), 784-809$.

Marucheck, A., Greis, N., Mena, C., \& Cai, L. (2011). Product safety and security in the global supply chain: Issues, challenges and research opportunities. Journal of Operations Management, 29(7-8), 707-720.

Narasimhan, R., \& Das, A. (1999). Manufacturing agility and supply chain management practices. Production and Inventory Management Journal, 40(1), 4.

Singh, N. P., \& Singh, S. (2019). Building supply chain risk resilience: Role of big data analytics in supply chain disruption mitigation. Benchmarking: An International Journal, 6(7),2318-2342.

Nguyen, T., Pham, T., Phan, T., \& Than, T. (2020). Impact of green supply chain practices on financial and non-financial performance of Vietnam's tourism enterprises. Uncertain Supply Chain Management, 8(3), 481-494.

Nagati, H., \& Rebolledo, C. (2013). Supplier development efforts: The suppliers' point of view. Industrial Marketing Management, 42(2), $180-188$.

Phan, T., Doan, X., \& Nguyen, T. (2020). The impact of supply chain practices on performance through supply chain integration in textile and garment industry of Vietnam. Uncertain Supply Chain Management, 8(1), 175-186.

Phan, T. T. H., Tran, H. X., Le, T. T., Nguyen, N., Pervan, S., \& Tran, M. D. (2020). The Relationship between Sustainable Development Practices and Financial Performance: A Case Study of Textile Firms in Vietnam. Sustainability, 12(15), 5930.

Pham, T., \& Phan, T. (2020). How to improve financial performance of tourism and travel enterprises: The case of Vietnam. Accounting, 6(3), 335-344.

Pfohl, H. C., \& Gomm, M. (2009). Supply chain finance: optimizing financial flows in supply chains. Logistics research, 1(3-4), 149-161.

Porter, M. E. (1990). The competitive advantage of nations. Competitive Intelligence Review, 1(1), 14-14.

Punniyamoorthy, M., Thamaraiselvan, N., \& Manikandan, L. (2013). Assessment of supply chain risk: scale development and validation. Benchmarking: An International Journal, 20(1), 79-105.

Revilla, E., \& Saenz, M. J. (2017). The impact of risk management on the frequency of supply chain disruptions: a configurational approach. International Journal of Operations \& Production Management, 37(5), 557-576.

Sharma, S., \& Routroy, S. (2016). Modeling information risk in supply chain using Bayesian networks. Journal of Enterprise Information Management, 29(2), 238-254.

Shen, B., \& Li, Q. (2017). Market disruptions in supply chains: a review of operational models. International Transactions in Operational Research, 24(4), 697-711.

Song, H., Yu, K., Ganguly, A., \& Turson, R. (2016). Supply chain network, information sharing and SME credit quality. Industrial Management \& Data Systems, 116(4), 740-758.

Song, H., \& Wang, L. (2013). The impact of private and family firms' relational strength on financing performance in clusters. Asia Pacific Journal of Management, 30(3), 735-748.

Subramani, M. (2004). How do suppliers benefit from information technology use in supply chain relationships?. MIS quarterly, 45-73.

Swaminathan, J. M., \& Tayur, S. R. (2003). Models for supply chains in e-business. Management Science, 49(10), 1387-1406.

Tagoe, N., Nyarko, E., \& Anuwa-Amarh, E. (2005). Financial challenges facing urban SMEs under financial sector liberalization in Ghana. Journal of Small Business Management, 43(3), 331-343.

Tomlinson, P. R. (2011). Strong ties, substantive embeddedness and innovation: Exploring differences in the innovative performance of small and medium-sized firms in UK manufacturing. Knowledge and Process Management, 18(2), 95-108.

Tran, M., Phan, T., Ha, H., \& Hoang, T. (2020a). The impact of transactional leadership on supply chain quality and performance. Uncertain Supply Chain Management, 8(4), 773-784.

Tran, M., Phan, T., Ha, H., \& Hoang, T. (2020b). The impact of supply chain quality integration on green supply chain management and environmental performance in Vietnam's tourism industries. Uncertain Supply Chain Management, 8(4), $693-704$.

Tanrisever, F., Erzurumlu, S. S., \& Joglekar, N. (2012). Production, process investment, and the survival of debt-financed startup firms. Production and Operations Management, 21(4), 637-652.

Wang, W. C., Teng, J. T., \& Lou, K. R. (2014). Seller's optimal credit period and cycle time in a supply chain for deteriorating items with maximum lifetime. European Journal of Operational Research, 232(2), 315-321.

Wuttke, D. A., Rosenzweig, E. D., \& Heese, H. S. (2019). An empirical analysis of supply chain finance adoption. Journal of Operations Management, 65(3), 242-261.

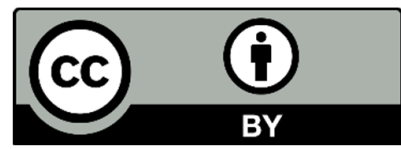

(C) 2022 by the authors; licensee Growing Science, Canada. This is an open access article distributed under the terms and conditions of the Creative Commons Attribution (CCBY) license (http://creativecommons.org/licenses/by/4.0/). 